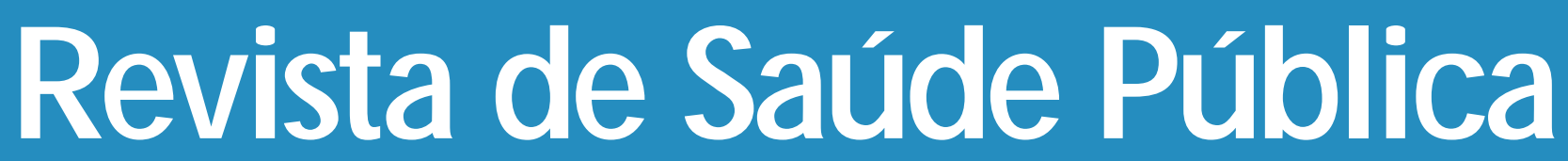

$\begin{array}{lllllll}J & 0 & \mathbf{U} & \mathbf{R} & \mathbf{N} & \mathbf{A} & \mathbf{L}\end{array}$

0 F

$\begin{array}{llllll}P & \mathbf{U} & \mathrm{B} & \mathrm{L} & \mathbf{I} & \mathbf{C}\end{array}$

H $\quad$ E $\quad A \quad L \quad T \quad H$

\title{
Formas imaturas de anofelíneos em recipientes artificiais*
}

\section{Immature forms of anophelines in artificial containers}

O swaldo Paulo Forattini, Iná Kakitani, Gisela Rita Alvarenga Monteiro Marques e Marylene de Brito

Departamento de Epidemiologia da Faculdade de Saúde Pública da Universidade de São Paulo.

São Paulo, SP - Brasil (O.P.F., I.K.), Superintendência de Controle de Edemias. Taubaté, SP (G.R.A.M.M., M.B.) 


\title{
Formas imaturas de anofelíneos em recipientes artificiais*
}

\section{Immature forms of anophelines in artificial containers}

\author{
O swaldo Paulo Forattini, Iná Kakitani, G isela Rita Alvarenga Monteiro Marques e \\ Marylene de Brito \\ Departamento de Epidemiologia da Faculdade de Saúde Pública da U niversidade de São Paulo. \\ São Paulo, SP - Brasil (O.P.F., I.K.), Superintendência de Controle de Edemias. Taubaté, SP \\ (G.R.A.M.M., M.B.)
}

\begin{abstract}
Resumo
Relata-se o encontro de formas imaturas de Anopheles bellator e de An. argyritarsis em recipientes artificiais. Considera-se, como fator importante, o grande número de recipientes descartáveis produzidos atualmente e que podem aumentar o número de criadouros viáveis para mosquitos culicídeos.
\end{abstract}

Anopheles. Ecologia de vetores.

\begin{abstract}
Immature stages of Anopheles bellator and of An. argyritarsis were found in artificial containers. The great number of on-returnable containers now produced, may be playing an important role in the increase in the number of available breeding places for culicid mosquitoes.
\end{abstract}

Anopheles. Vector ecology.

De maneira geral, os anofelíneos das Américas não adotaram os recipientes como habitats para o desenvolvimento de suas formas imaturas. Algumas espécies, como Anopheles barberi e An. eiseni têm sido assinaladas em ocos de árvores, a segunda de maneira esporádica (Bates ${ }^{1}$, 1949; Horsfall ${ }^{3}$, 1972; Chambers $^{2}$, 1985). Contudo e em relação a recipientes naturais, são exceções os representantes do subgênero Kerteszia dentre os quais, Anopheles bellator e An. cruzii que se utilizam de bromélias, enquanto An. bambusicolus adaptou-se a internódios de bambu. De qualquer maneira, no estado atual dos conhecimentos, considera-se como anômalo o encontro de anofelíneos criando-se em recipientes artifici- ais. Destes achados, em nosso meio, pode-se mencionar os concernentes a An. cruzii observado em vasos de barro na área de Paranaguá e a $A n$. bambusicolus criando-se em pneus abandonados ou utilizados como armadilhas para ovos (APO) em Foz do Iguaçu, ambas regiões pertencentes ao Estado do Paraná, Brasil (Luz e col. $\left.{ }^{4}, 1987\right)$.

Durante a execução de programa de pesquisas objetivando observar o comportamento de culicídeos potencialmente vetores de infecções, no Estado de São Paulo, Brasil, houve ocasiões nas quais foram encontradas formas imaturas de anofelíneos em recipientes artificiais. Duas ocorreram na localidade de Pedrinhas, no Município de Ilha Comprida. Os

* Subvencionado pela Fundação de Amparo à Pesquisa do Estado de São Paulo / FAPESP (Processo Temático n 95/0381-4) e pelo Conselho Nacional de Desenvolvimento Científico e Tecnológico/CNPq (Bolsa de Produtividade em Pesquisa - Processo no 3000225/95-4).

Correspondência para/Correspondence to: Oswaldo Paulo Forattini - Núcleo de Pesquisa Taxonômica e Sistemática em Entomologia Médica/

NUPTEM - Av. Dr. Arnaldo, 715 - 01246-904 - São Paulo, SP - Brasil. E-mail: opforati@usp.br

Edição subvencionada pela FAPESP (Processo n 97/09815-2).

Recebido em 13.4.1998. Aprovado em 7.5.1998. 
encontros tiveram lugar em um dos criadouros experimentais que ali foram instalados com a finalidade de se observar a evolução desses habitats no que concerne à presença de formas imaturas. Esse criadouro era representado por caixa d'água, com volume líquido constantemente mantido com cerca de 70 litros. Originalmente colocou-se água destilada proveniente do laboratório. Nas inspeções realizadas em 26/02/98 e 10/03/98 foi possível coletar duas larvas e uma pupa feminina de Anopheles bellator. A pupa morreu antes de dar saída ao adulto. Uma das larvas transformou-se em pupa e, no laboratório, deu origem à espécime adulto masculino. Essas formas conviviam com cerca de outras 97 de Aedes albopictus, somados os dados referentes às duas coletas. Esse recipiente foi instalado em ambiente peridomiciliar, sob pequeno telheiro feito para evitar a entrada de água das precipitações atmosféricas (Fig.1).

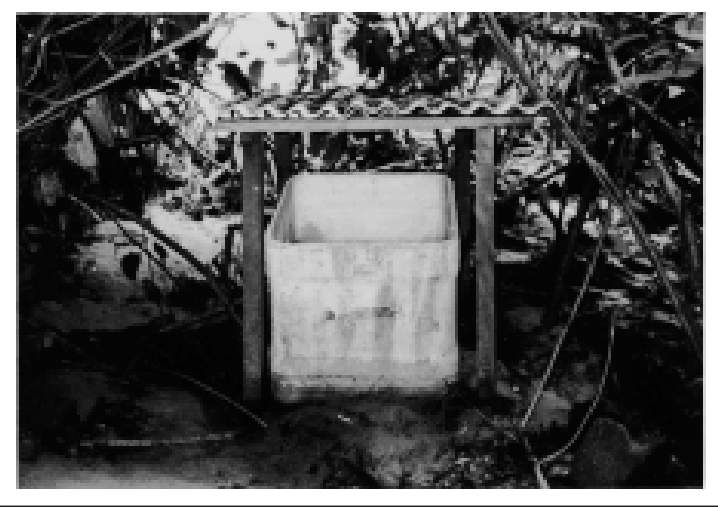

Figura 1- Criadouro experimental instalado em peridomicílio da localidade de Pedrinhas, Município de Ilha Comprida, Estado de São Paulo, Brasil, no qual foram encontradas formas imaturas de Anopheles bellator. N otese a existência de pequeno telheiro à guisa de cobertura para evitar a interferência das precipitações atmosféricas.

Outra observação foi feita em depósito ou entreposto de vasilhames e de materiais usados, para comercialização, na cidade de Pindamonhangaba, em 03/03/98. As coletas foram realizadas em cerca de dez litros acumulados em recipiente representado por caixa d'água ali depositada e com a capacidade volumétrica total de aproximadamente 80 litros. Nessa ocasião foram coletadas 274 formas imaturas, das quais 205 de Aedes albopictus, 67 de Culex quinquefasciatus e duas identificadas como sendo de Anopheles argyritarsis. Esse recipiente, que representou o papel de criadouro para esses mosquitos, era um dos inúmeros dispostos desordenadamente no referido depósito como mostra o detalhe apresentado pela Figura 2.
A interpretação desses encontros presta-se a muitas discussões. Em se tratando de anofelíneos Kerteszia, como An. cruzii observado em Paranaguá criando-se em vasos de barro, Luz e col'. (1987) aventaram a hipótese das larvas serem originárias de fêmeas chegadas acidentalmente à área, a qual seria desprovida de bromélias. Em vista disso, viram-se forçadas à opção para a desova naqueles recipientes artificiais. Quanto a An. bambusicolus, os mesmos autores atribuem os achados à maior valência ecológica do anofelíneo o qual, portanto, apresentaria maior capacidade de adaptação ao ambiente antrópico. Não obstante, os presentes achados concernentes a An. bellator dificilmente poderiam encontrar explicação na ausência de bromélias. Elas são abundantes na região e mesmo na proximidade da caixa d'água, onde foram encontradas as formas imaturas. Talvez, o pequeno telheiro, que serve de abrigo, possa ter induzido a certa semelhança com recipientes naturais.

Quanto à segunda dessas observações e relativa a An. argyritarsis, pelo que se sabe tradicionalmente trata-se de mosquito cujas formas imaturas têm mostrado preferências por coleções líquidas no solo. Além disso, os criadouros normalmente apresentam água limpa, ao abrigo das excessivas elevações da temperatura ambiente, com vegetação emergente e dotadas de certa movimentação líquida (Horsfall ${ }^{3}$, 1972). Dessa maneira, o encontro em recipiente artificial e em companhia de $C x$. quinquefasciatus, contradiz essas características. Acresce considerar que a região do Vale do Paraíba, onde se situa a cidade de Pindamonhangaba, oferece numerosos locais, na pe-

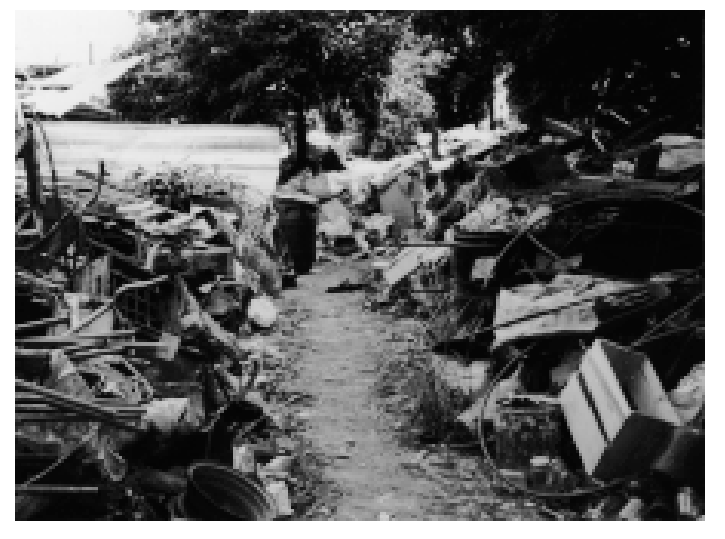

Figura 2- Aspecto do entreposto situado na cidade de Pindamonhangaba, Estado de São Paulo, Brasil. Pode-se notar a disposição desordenada de recipientes e de materiais usados, os mais variados e dentre os quais estava a caixa d'água que albergava larvas de Anopheles argyritarsis. 
riferia suburbana, com viabilidade para a instalação de criadouros desse anofelíneo.

Face a tais observações, torna-se forçoso considerar o atual estado cultural da sociedade humana. Esta bem pode ter como um de seus caracteres o excessivo número de recipientes descartáveis. Estando em plena era daquilo que se poderia chamar de "Era do Plástico", a humanidade notabiliza-se nos dias que correm pela produção de grande número de objetos e implementos, todos de caráter transitório. Se bem que em países ricos eles venham a ser desprezados por inservíveis, em outros, como o nosso, adquirem

\section{REFERÊNCIAS}

1. BATES, M. The natural history of mosquitoes. New York, Macmillan, 1949.

2. CHAMBERS, R.C. Competition and predation among larvae of three species of threehole-breeding mosquitoes. In: Lounibos, L.P.; Rey, J.R.; Frank, J.H., ed. Ecology of mosquitoes: proceedings of a workshop. Vero Beach, Florida Medical Entomology Laboratory, 1985. p. 25-53. certo valor comercial após o uso. Daí o acúmulo em determinados locais, chamados geralmente de "entrepostos", onde são armazenados para serem comercializados. É o que se pode ver na Figura 2. Assim sendo, torna-se lícito levantar a hipótese de que esse grande número de recipientes fabricados pelo homem, e posteriormente descartados, venha a potencializar grandemente a oferta de locais de criação para culicídeos. Tais reflexıes vêm muito a propósito, diante da atual epidemia de dengue que assola o nosso País.

3. HORSFALL, W.R. Mosquitoes: their bionomics and relation to disease. New York, Hafner Publishing, 1972.

4. LUZ, E.; CONSOLIM, J.; BARBOSA, O.C.; TORRES, P.B. Larvas de Anopheles (Subgênero Kerteszia) Theobald 1905 encontradas em criadouros artificiais, no Estado do Paraná, Brasil. Rev. Saúde Pública, 21:466-8, 1987. 